\title{
Antimicrobial Susceptibility Pattern of Urinary Pathogens in a Tertiary Care Hospital
}

\author{
Akshatha N. ${ }^{1}$, Anjana Gopi ${ }^{2}$, Supriya Christopher ${ }^{3}$, Mangala G.K. ${ }^{4}$ \\ 1,2,3 Department of Microbiology, Kempegowda Institute of Medical Sciences \\ (KIMS), Bengaluru, Karnataka, India. ${ }^{4}$ Department of Microbiology, Jagadguru Jayadeva \\ Murugarajendra Medical College (JJMMC), Davangere, Karnataka, India.
}

\section{ABSTRACT}

\section{BACKGROUND}

Urinary tract Infection (UTI) are the most common clinical conditions in general practice and gynaecological department. Men and women of all age groups are affected by UTI, but its overall prevalence is higher in women. The major causative agents are Escherichia coli and other Enterobacteriaceae. In majority of the cases, empirically treatment is started with antimicrobials before the urine culture and sensitivity reports become available. This has led to an increase in antibiotic resistance in urinary pathogens. Hence, the present study was undertaken to determine the antimicrobial susceptibility pattern of uropathogens to commonly used antimicrobials in treating UTIs.

\section{METHODS}

A total of 200 urine samples were obtained from patients with signs and symptoms suggestive of UTIs attending Bapuji and Chigateri General Hospital which are attached to Jagadguru Jayadeva Murugarajendra Medical College (JJMMC), Davangere for a period of 3 months that is from May 2016 to July 2016. Urine samples were processed within 2 hours of reaching the laboratory. Semi quantitative urine culture was done. Isolation and identification were done by performing standard biochemical tests and the antimicrobial susceptibility testing was done using the standard disc diffusion method by Kirby-Bauer technique.

\section{RESULTS}

There were 170 urinary isolates from 200 samples. Children less than 10 years were more affected 54 (27\%). Female patients were more, 119 (59.5\%) compared to males 81 (40.5\%). Escherichia coli was the most predominant isolate, 71 (41.8\%) followed by Enterococcus species 22 (1.9\%). Organisms were resistant to commonly used antibiotics i.e., cotrimoxazole, ciprofloxacin, norfloxacin and amoxicillin. Both gram negative and gram-positive isolates were sensitive to amikacin and nitrofurantoin.

\section{CONCLUSIONS}

In present study Escherichia coli is the predominant pathogen. Uncomplicated UTIs can be empirically treated by nitrofurantoin. Occurrence of treatment failure with commonly used antimicrobials is more often in Indian setting. Hence, antimicrobial susceptibility testing must be employed routinely.

\section{KEY WORDS}

UTIs, Uropathogens, E. coli, Antimicrobial Susceptibility Pattern
Corresponding Author: Dr. Supriya Christopher, Professor,

Department of Microbiology, Kempegowda Institute of Medical Sciences (KIMS), Banashankari $2^{\text {nd }}$ Stage, Bengaluru - 560070, Karnataka, India. E-mail: supriyachristopher@hotmail.com

DOI: $10.14260 / j e m d s / 2021 / 189$

How to Cite This Article:

Akshatha N, Gopi A, Christopher S, et al. Antimicrobial susceptibility pattern of urinary pathogens in a tertiary care hospital. J Evolution Med Dent Sci 2021;10(12):878-882, DOI: $10.14260 / \mathrm{jemds} / 2021 / 189$

Submission 20-09-2020,

Peer Review 17-01-2021,

Acceptance 23-01-2021,

Published 22-03-2021.

Copyright @ 2021 Akshatha N. et al. This is an open access article distributed under Creative Commons Attribution License [Attribution 4.0 International (CC BY 4.0)] 


\section{BACKGROUND}

In general and gynaecological practices, urinary tract infection are common clinical conditions.1,2,3 Men and women of all age groups are affected by UTI, but its overall prevalence is higher in women i.e., 20 - $50 \%$ of them will have a clinical episode during their lifetime.4,5,6 An estimated $20 \%$ of all UTIs occur in men. ${ }^{7}$ At least one episode of UTI is seen in about $5-6 \%$ of girls between their first grade to high school and nearly $80 \%$ of them experience recurrent infections. ${ }^{1}$

Each year about 150 million people are diagnosed with UTI worldwide, which are classified as complicated or uncomplicated. ${ }^{8}$ Complicated UTIs are infections that will prolong treatment need or there are therapeutic failure chances because of the urinary tract abnormalities that obstruct urine flow, the foreign body in situ (e.g., indwelling catheter, stone), or infection caused by multidrug resistant strains and also associated with co-morbid conditions. Infections in male patients are considered complicated. Uncomplicated UTI is seen in sexually active healthy female patients with normal structural and functional urinary tracts. In a healthy patient UTI involving the upper urinary tract, pyelonephritis can be considered uncomplicated.9,10

Bacteriuria along with urinary symptoms is UTI. ${ }^{11}$ It involves both the upper and lower urinary tract or only the lower tract. Cystitis is the lower UTI characterised by dysuria, frequency, urgency and occasionally suprapubic tenderness. ${ }^{12}$ UTI can be either asymptomatic bacteriuria or symptomatic infection with invasion of bacteria and urinary tract inflammation. ${ }^{13}$ Symptomatic bacteriuria is patient who have symptoms referable to the urinary tract. Asymptomatic bacteriuria is a patient without classical symptoms and presence of bacteria in two consecutive clear voided urine specimens both yielding positive cultures $\left(>10^{5} \mathrm{cfu} / \mathrm{mL}\right.$ ) of the same pathogen ${ }^{14}$ Up to $90 \%$ of the patients complain of symptoms of UTI among them one third or more patients do not have bacteriuria. ${ }^{15}$ The diagnosis of UTI by history alone is done by symptoms of dysuria and frequency which together raise the probability of UTI to more than $90 \% .16$

The major causative agents of UTIs are Escherichia coli ${ }^{17,18}$ and other Enterobacteriaceae. In some hospitalised patients, pseudomonas species and gram-positive cocci like Enterococcus species, coagulase negative staphylococci, Staphylococcus aureus are comparatively more common. .3,19,20 $^{2}$

In majority of the cases, empirically treatment is started with antimicrobials before the availability of urine culture and sensitivity reports. This has led to an increase in antibiotic resistance in urinary pathogens. This is due to indiscriminate use of antibiotics, over the counter availability of higher antibiotics, poor sanitation, high prevalence of diarrhoea, overcrowding and poor facility to conduct antibiotic sensitivity surveillance in hospitals. ${ }^{21,22}$

The overall idea of the aetiological agents causing urinary tract infections and their antibiotic resistance patterns may help the clinicians in starting the empirical treatment for UTIs using appropriate antibiotics. Hence, the present study is undertaken in finding out the UTI prevalence and to determine the antimicrobial susceptibility pattern of uropathogens to commonly used antimicrobials in treating UTIs.

\section{METHODS}

This is a descriptive study to determine the antimicrobial susceptibility pattern of urinary pathogens to commonly used antimicrobials in treating UTIs in a tertiary care hospital.

\section{Study Area \& Duration}

By purposive / convenient sampling technique, 200 urine samples from patients with signs and symptoms suggestive of UTIs attending Bapuji and Chigateri General Hospital which are attached to JJM Medical College, Davangere are considered for the study. The duration of study was 3 months period from May 2016 to July 2016.

\section{Processing of Sample}

Urine samples were processed within 2 hours of reaching the laboratory. Using a standard calibrated bacteriological loop, semi quantitative urine culture was done. A well-mixed uncentrifuged urine with loop $(0.001 \mathrm{~mL})$ was taken and culture was done by inoculating on cysteine lactose electrolyte deficient medium (CLED). After which the culture was incubated at $37^{\circ} \mathrm{C}$ aerobically for 24 hours and colony count was considered by expressing as colony forming units (cfu) per millilitre $(\mathrm{mL})$. A pure culture of a single bacterium with colony count of $\geq 10^{5} \mathrm{cfu} / \mathrm{mL}$ and microscopy findings of pus cells $>10$ per oil immersion field is considered as significant bacteriuria. $^{23}$ The culture isolates were identified by performing the standard biochemical methods. ${ }^{24}$

Isolates were tested for antimicrobial susceptibility testing by the standard Kirby-Bauer disc diffusion method according to Bauer et al. ${ }^{25}$ The following standard antibiotic discs were used. Amikacin (30 mcg), amoxycillin (30 mcg), gentamycin (10 mcg), cotrimoxazole (25 mcg), nitrofurantoin (300 mcg), norfloxacin $(10 \mathrm{mcg})$, ciprofloxacin $(5 \mathrm{mcg})$, cefotaxime $(30$ $\mathrm{mcg}$ ), nalidixic acid (mcg), linezolid (30 mcg), cefoxitin (mcg), imipenem (10 mcg), meropenem (10 mcg), ceftazidime / clavulanic acid (30 / 10 mcg), cefoperazone / sulbactam (75 / $30 \mathrm{mcg}$ ) and ceftriaxone / sulbactam (30/15 mcg).

Antimicrobial discs were obtained from HiMedia Laboratories Pvt. Ltd, Mumbai, India. The results were interpreted according to Clinical and Laboratory Standards Institute guidelines (CLSI 2016). ${ }^{26}$ The American type culture collection (ATCC) strains of Escherichia coli 25922, Pseudomonas aeruginosa 27853, Enterococcus faecalis 29212 and Staphylococcus aureus 25923 for antimicrobial discs were used as the quality control.

\section{Statistical Analysis}

Descriptive statistics was used which includes frequency / percentage of antimicrobial susceptibility pattern of urinary pathogens. Data entered in Microsoft Excel and statistical analysis was done from software SPSS version 20.

\section{RESULTS}

During the period of 3 months, out of the 200 urine samples, growth of 170 urinary isolates were considered leaving behind 
no growths, sample contamination and non-significant bacteriuria.

\section{Age}

Out of 200 urine samples, there were age group of people ranging from less than 10 years to more than 60 years. Of which children less than 10 years of age were more with UTI accounting for 54 (27\%) and age group of $11-20$ years were least infected accounting for 13 (6.5\%).

\begin{tabular}{|ccc|}
\hline Age in Years & No. of Patients with UTI & Percentage \\
$<10$ & 54 & $27 \%$ \\
$11-20$ & 13 & $6.5 \%$ \\
$21-30$ & 39 & $19.5 \%$ \\
$31-40$ & 25 & $12.5 \%$ \\
$41-50$ & 18 & $09 \%$ \\
$51-60$ & 18 & $09 \%$ \\
$>60$ & 33 & $16.5 \%$ \\
Total & 200 & $100 \%$ \\
\hline \multicolumn{2}{|c}{ Table 1. Age Wise Distribution of Urine Samples } \\
\hline
\end{tabular}

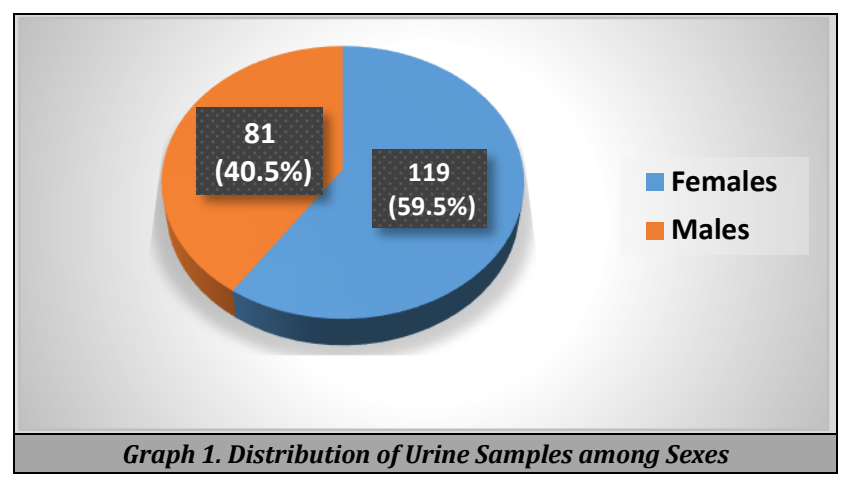

\section{Gender}

$119(59.5 \%)$ were female patients and the remaining 81 (40.5 $\%)$ were male patients.

\section{Isolates}

Among 170 urinary isolates, gram-negative bacteria accounted for 125 (73.5\%) comprising of Escherichia coli 71 (41.8\%), pseudomonas species 20 (11.8\%), klebsiella species 25 (14.7\%), acinetobacter species 08 (4.7\%) and proteus species $01(0.6 \%)$. While gram-positive bacteria accounted for 45 (26.5\%) comprising of Enterococcus species 22 (12.9\%), Staphylococcus aureus 04 (2.3 \%), coagulase negative staphylococcus (CoNS) 18 (10.6\%) and alpha-haemolytic streptococci (viridans streptococci) $01 \quad(0.6 \quad \%)$. The predominant causative agent of UTI was Escherichia coli followed by klebsiella species, pseudomonas species and gram-positive bacteria. Among S. aureus 04 (2.3\%), methicillin sensitive $S$. aureus (MSSA) were $01(0.6 \%)$ and methicillin resistance $S$. aureus (MRSA) were $03(1.7 \%)$ and CoNS were 18 (10.6\%).

\section{Antimicrobial Susceptibility Profiles of Bacterial Isolates \\ Overall, gram positive isolates showed high sensitivity to nitrofurantoin, ciprofloxacin, gentamycin and amikacin when compared to gram-negative isolates and enterococci.}

E. coli was resistant to most commonly used antimicrobials i.e., cotrimoxazole, ciprofloxacin, nitrofurantoin and amoxycillin with a sensitivity pattern of $29.6 \%, 16.9 \%, 14 \%$ and $1.4 \%$ respectively. It showed high sensitivity to amikacin and nitrofurantoin (77.5 \% each) followed by gentamycin (56.3 $\%)$.

\begin{tabular}{|c|c|c|c|}
\hline Antimicrobials & $\begin{array}{c}\text { No }(\%) \text { Sensitive } \\
\text { for } E \text {. coli }(\mathrm{N}= \\
71)\end{array}$ & $\begin{array}{c}\text { GNB's } \\
(\mathrm{N}=125)\end{array}$ & $\begin{array}{c}\text { GPC's } \\
(\mathrm{N}=45)\end{array}$ \\
\hline Amikacin & $55(77.5 \%)$ & $95(76 \%)$ & $19(42.2 \%)$ \\
\hline Nitrofurantoin & $55(77.5 \%)$ & $72(58 \%)$ & $12(26.6 \%)$ \\
\hline Gentamycin & $40(56.3 \%)$ & $72(58 \%)$ & $17(37.7 \%)$ \\
\hline Cotrimoxazole & $21(16.9 \%)$ & $40(32 \%)$ & $16(35.5 \%)$ \\
\hline Ciprofloxacin & $12(16.9 \%)$ & $39(31 \%)$ & $17(37.7 \%)$ \\
\hline Norfloxacin & $10(14 \%)$ & $30(24 \%)$ & $04(8.8 \%)$ \\
\hline Amoxicillin & $01(1.4 \%)$ & $02(1.2 \%)$ & $12(26.6 \%)$ \\
\hline Nalidixic acid & $03(4.2 \%)$ & $09(7.2 \%)$ & $\begin{array}{l}\text { Linezolid (Lz) } \\
-04(8.8 \%)\end{array}$ \\
\hline Imipenem & $14(19.7 \%)$ & $22(17.6)$ & $02(4.4 \%)$ \\
\hline Meropenem & $01(1.4 \%)$ & $06(4.8 \%)$ & $01(2.2 \%)$ \\
\hline Cefotaxime & $10(14 \%)$ & $26(20.8 \%)$ & $\begin{array}{c}\text { Ctx-16 }(35.5 \%) \\
\text { Cefoxitin (Cx) } \\
-03(6.6 \%)\end{array}$ \\
\hline $\begin{array}{l}\text { Ceftazidime / } \\
\text { clavulanic acid }\end{array}$ & 05 (7 \%) & $12(9.6 \%)$ & $02(4.4 \%)$ \\
\hline $\begin{array}{l}\text { Cefoperazone / } \\
\text { sulbactam }\end{array}$ & $02(2.8 \%)$ & $07(5.6 \%)$ & $01(2.2 \%)$ \\
\hline Ceftriaxone / sulbactam & $03(4.2 \%)$ & $06(4.8 \%)$ & $01(2.2 \%)$ \\
\hline
\end{tabular}

\begin{tabular}{|ccc|}
\hline Microorganisms & Frequency & Percentage \\
E. coli & 71 & 41.8 \\
Klebsiella spp & 25 & 14.7 \\
Pseudomonas spp & 20 & 11.8 \\
Acinetobacter spp & 08 & 4.7 \\
Proteus spp & 01 & 0.6 \\
Total GNB's isolated & 125 & 73.6 \\
Enterococcus spp & 22 & 12.9 \\
CoNS & 18 & 10.6 \\
S. aureus & 04 & 2.3 \\
$\alpha$-haemolytic streptococci & 01 & 0.6 \\
Total GPC's isolated & 45 & 26.4 \\
Total isolates both GNB and GPC & 170 & 100 \\
\hline Table 3. Distribution of Various Pathogens Isolated from UTI Patients \\
\hline
\end{tabular}

\section{DISCUSSION}

Present study is conducted to determine the UTI prevalence, common etiological agents and their susceptibility profile. This gives valuable information in monitoring the antimicrobial resistance pattern among uropathogens and also to improve the treatment recommendations.

The age group analysis showed that young children aged less than 10 years had highest prevalence ( $27 \%$ ) of UTI. This is similar with the studies done by Umesh et al. ${ }^{27}$ and Akash $\mathrm{S}^{28}$ which states that in infants and children, UTI is the common serious bacterial infections which troubles the child and concerns the parents by presenting as asymptomatic bacteriuria to potentially life-threatening infection of the kidney. ${ }^{29}$ Next age group which showed high prevalence was among female patients aged between 21 and 30 years $(19.5 \%)$ of UTI which is similar to studies done by Muktikesh Dash ${ }^{19}$ and Uma Gupta. ${ }^{13}$ The high incidence of symptomatic UTI is seen in sexually active young women and increased risk is seen with act of sexual coitus, usage of diaphragm with spermicide 
and a recurrent UTIs history. ${ }^{9}$

In the present study, the prevalence of UTI is $85 \%$. It is higher among females (59.5\%) in comparison with the males (40.5\%). This is similar to other studies done by Muktikesh dash et al. ${ }^{19}$ Urvashi Chongtham, ${ }^{21}$ Zahra Tayebiet al. ${ }^{30}$ and Sunil Kumar D Chavan which states this is because of sexual intercourse, the close distance of the urethral meatus to anus and short urethra of females. ${ }^{31}$

In this study, among gram negative bacilli (73.5 \%), E. coli (41.8\%) is the commonest uropathogen responsible for UTI which is followed by klebsiella species (14.7\%). This finding were almost in agreement with other studies by Urvashi Chongtham ${ }^{21}$ who reported E. coli $(43.16 \%)$ and klebsiella species (17.89\%), and also studies by Uma Gupta ${ }^{13}$ and Muktikesh Dash. ${ }^{19}$ The next most common organism was Enterococcus species accounting for $12.9 \%$ which is similar to those reported in previous studies. ${ }^{8,19}$ This finding was in agreement with other studies by Zahra Tayebi ${ }^{30}$, Sunil Kumar D Chavan ${ }^{31}$ and "Katarzyna Hryniewicz. ${ }^{32 \text { " }}$

The Infectious Disease Society of America Guidelines states that as current standard empirical therapy, drugs such as fluoroquinolones, cotrimoxazole, nitrofurantoin and $\beta$ lactams including amoxicillin clavulanic acid (Augmentin), cefdinir, cefaclor, cephalexin, cefpodoxime-proxetil can be given. ${ }^{33}$

In the present study, $E$. coli showed low sensitivity to commonly used empirical antibiotics such as $\beta$ lactams, fluroquinolones and cotrimoxazole which is similar to study done by Muktikesh Dash. ${ }^{19}$ Aminoglycosides (gentamycin and amikacin) showed high sensitivity rate of $58 \%$ \& $80 \%$ respectively for $E$. coli. In community-care setting, these are less commonly used as they need injectable route of administration.

In the present study, amikacin and nitrofurantoin showed high sensitivity rate which is similar to study done by Muktikesh Dash. ${ }^{19}$ Hence, nitrofurantoin can be used as the ideal antibiotic of choice for UTI. But its use as oral formulation is limited for complicated upper UTI or for those patients with systemic involvement. 5

\section{CONCLUSIONS}

In specific geographical regions it is difficult to treat UTI empirically because of decreased susceptibility rates documented for common uropathogens. Hence, antimicrobial susceptibility patterns of uropathogens should be considered in antimicrobial selection for UTIs. Occurrence of treatment failure with commonly used antimicrobials is more common in Indian setting. Therefore, routine urine culture is advisable with antimicrobial susceptibility testing along with development of UTI guidelines.

Data sharing statement provided by the authors is available with the full text of this article at jemds.com.

Financial or other competing interests: None.

Disclosure forms provided by the authors are available with the full text of this article at jemds.com.

\section{REFERENCES}

[1] Kunin CM. Urinary tract infecions and pyelonephrities. In: Bennett JC, Plum F, eds. Cecil Textbook of Medicine. Vol. 2. $20^{\text {th }}$ edn. Philadelphia: W.B. Saunders Company, 1996: p. 602-5.

[2] Stamm WE. Urinary tract infections and pyelonephritis. In: Isselbacher KJ, Braunwald E, Wilson JD, eds. Harrison's Principles of Internal Medicine. Vol. 1. 13 ${ }^{\text {th }}$ edn. New York: McGraw-Hill 1994: p. 548-53.

[3] Gastmeier P. Nosocomial urinary tract infection: many unresolved questions. Clin Microbiol Infect 2001;7(10):521-2.

[4] Rock W, Colodner R, Chazan B, et al. Ten years surveillance of antimicrobial susceptibility of community acquired Escherichia coli and other uropathogens in northern Israel (1995-2005). Isr Med Assoc J 2007;9(11):803-5.

[5] Vasquez Y, Hand WL. Antibiotic susceptibility patterns of community - acquired urinary tract infection isolates from female patients on the US (Texas) Mexico Border. J Appl Res 2004;4(2):321-6.

[6] Cumming AD, Swainson CP, Davidson AM. Infections of the kidney and urinary tract. In: Edwards CR, Bouchier IA, Haslett C, eds. Davidson's Principles and Practice of Medicine. 17th edn. Edinburgh: ELBS / Churchill Livingstone 1995: p. 649-55.

[7] Griebling TL. Urinary tract infection in men. In: Litwin MS, Saigal CS, eds. Urology Diseases in America. DHHS, PHS, NIH, NIDDK. Washington DC: GPO 2007: p. 621-45.

[8] Stamm WE, Norrby SR. Urinary tract infections: disease panorama and challenges. J Infect Dis 2001;183(Suppl 1):S1-S4.

[9] Hooton TM. Pathogenesis of urinary tract infections: an update. J Antimicrob Chemother 2000;46(Suppl 1):1-7.

[10] Stapleton AE. Urinary tract infections in healthy women. Curr Treat Opt Infect Dis 2003;5:43-51.

[11] Zelikovic I, Adelman RD, Nancarrow PA. Urinary tract infections in children. An update. West J Med 1992;157(5):554-61.

[12] Sobel JD, Kaye D. Urinary tract infections. In: Mandell GL, Bennett JE, Dolin R, eds. Mandell, Douglas and Bennett's Principles and practice of infectious diseases. $7^{\text {th }}$ edn. Philadelphia: Churchill Livingstone 2010: p. 957-85.

[13] Shaifali I, Gupta U, Mahmood SE, et al. antibiotic susceptibility patterns of urinary pathogens in female outpatients. N Am J Med Sci 2012;4(4):163-9.

[14] Patterson TF, Andriole VT. Bavteriuria in pregnancy. Infectious Disease Clin North America 1987;1(4):807-22.

[15] Medina-Bambardo D, Segui-Diaz M, Roca-Fusalba C, et al. What is the predictive value of urinary symptoms for diagnosing urinary tract infection in women? Fam Pract 2003;20(2):103-7.

[16] Bent S, Nallamothu BK, Simel DL, et al. Does this woman have an acute uncomplicated urinary tract infection? JAMA 2002;287(20):2701-10.

[17] Jellheden B, Norrby RS, Sandberg T. Symptomatic urinary tract infection in women in primary health care: Bacteriological, clinical and diagnostic aspects in relation to host response to infection. Scand J Prim Health Care 1996;14(2):122-8. 
[18] Ronald A. The etiology of urinary tract infection: traditional and emerging pathogens. The Am J Med 2002;113(Suppl 1A):14S-9S.

[19] Muktikesh D, Sanghamitra P, Indrani M, et al. Antimicrobial resistance in pathogens causing urinary tract infections in a rural community of Odisha, India. J Family Community Med 2013;20(1):20-6.

[20] Urvashi C, Chitra Y, Lokhendro H. Bacterial uropathogens in urinary tract infection and antibiotic susceptibility pattern of patients attending jnims hospital, Imphal. Journal of Evolution of Medical and Dental Sciences 2013;2(50): p. 9769-9774.

[21] Tambekar DH, Dhanorkar DV, Gulhane SR, et al. Antimicrobial susceptibility of some urinary tract pathogens to commonly used antibiotics. Afr J Biotechnol 2006;5(17):1562-5.

[22] Ghafur AK. An obituary - on the dealth of antibiotics. J Assoc Physicians India 2010;58:143-4.

[23] Kass EH. Bacteriuria and the diagnosis of infections of the urinary tract; with observations on the use of methionine as a urinary antiseptic. AMA Arch Intern Med 1957;100(5):709-14.

[24] Collee JG, Miles RS, Watt B. Tests for identification of bacteria. In: Collee JG, Fraser AG, Marmion BP, et al. eds. Mackie and McCartney Practical Medical Microbiology. 14th edn. Singapore: Churchill Livingstone 2006: p. 13149.

[25] Bauer AW, Kirby WM, Sherris JC, et al. Antibiotic susceptibility testing by a standardized single disk method. Am J Clin Pathol 1966;45(4):493-6.

[26] Clinical and Laboratory Standards Institute (CLSI). Performance Standards For Antimicrobial Susceptibility
Testing. Document M100, Supplement 19. Wayne, PA: USA: Clinical and Laboratory Standards Institute, 2016.

[27] Umesh, Padmavati B, Sushma T. Microbiological Profile in Urinary Tract Infections among Children in a Tertiary Care Center in Kumaun region, India. Int J Curr Microbiol App Sci 2016;5(4):101-108.

[28] Akash S, Adarsh E. Clinico-microbiological profile of uti in children less than 10 years in department of pediatrics in tertiary care centre. Journal of Evolution of Medical and Dental Sciences 2014;3(15):3874-3882.

[29] Chang SL, Shortliffe LD. Pediatric urinary tract infections. Pediatric Clin North America 2006;53(3):379-400.

[30] Tayebi Z, Seyedjavadi SS, Goudarzi M, et al. Frequency and antibiotic resistance pattern in gram positive uropathogenes isolated from hospitalized patients with urinary tract infection in Tehran, Iran. Journal of Genes, Microbes and Immunity 2014;2014:1-9.

[31] Lakshminarayana SA, Chavan SKD, Prakash R, et al. Bacterial pathogens in urinary tract infection and antibiotic susceptibility pattern from a teaching hospital, Bengaluru, India. Int J Curr Microbiol App Sci 2015;4(11):731-6.

[32] Hryniewicz K, Szczypa K, Sulikowska A, et al. Antibiotic susceptibility of bacterial strains isolated from urinary tract infections in Poland. Journal of Antimicrobial Chemotherapy 2001;47(6):773-80.

[33] Gupta K, Hooton TM, Naber KG, et al. International clinical practice guidelines for the treatment of acute uncomplicated cystitis and pyelonephritis in women: a 2010 update by the Infectious Diseases Society of America and the European Society for Microbiology and Infectious Diseases. Clin Infect Dis 2011;52(5):e103-20. 